\title{
Pemanfaatan Plugin After Effect Untuk Produksi Film
}

\author{
Supriyadi \\ STMIK Nusa Mandiri Jakarta \\ spy2adi@gmail.com
}

Cara Sitasi: Supriyadi. (2019). Pemanfaatan Plugin After Effect Untuk Produksi Film. Jurnal Komunikasi, 10(1), 33-41.

\begin{abstract}
Film is a communication media that is audio visual in nature to convey a message to a group of people who gather in a certain place. Movie messages on mass communication can take the form of anything depending on the film's mission. However, generally a film can include a variety of messages, both messages of education, entertainment and information. The message in the film is to use the mechanism of symbols that exist in the human mind in the form of message content, voice, words, conversations and so on. Trailer is a preview or excerpts of interesting scenes from a film, which aims to attract the audience to want to see the film that is. While the development of the world of film itself in recent years is very rapidly advancing. Lots of interesting scenes that are very extraordinary are shown on some of the leading films in the world today. Like the trailer on Aquaman and Avenger's films, wherein there are scenes showing an engineering city that resembles the original in the story and explosions that destroy buildings or the surrounding environment. It is impossible for such places to exist on this earth. The making of special effects as in the scenes will later use the technique of implementing essential elements in footage movie action in Adobe After Effect and several plugins that support it. At the end of the project it will produce a trailer, where later the processing techniques can inspire young Indonesian filmmakers as learning media in the field of film. It can also be used as a new method for reprocessing an event that is not possible by directly reconstructing it using ordinary video.
\end{abstract}

Keywords : special effect, trailer, adobe after effect, plugin

\section{PENDAHULUAN}

Film adalah media komunikasi yang bersifat audio visual untuk menyampaikan suatu pesan kepada sekelompok orang yang berkumpul di suatu tempat tertentu. (Effendy, 2011).

Pesan film pada komunikasi massa dapat berbentuk apa saja tergantung dari misi film tersebut. Akan tetapi, umumnya sebuah film dapat mencakup berbagai pesan, baik itu pesan pendidikan, hiburan dan informasi. Pesan dalam film adalah menggunakan mekanisme lambing-lambang yang ada pada pikiran manusia berupa isi pesan, suara, perkataan, percakapan dan sebagainya.

Film juga dianggap sebagai media komunikasi yang ampuh terhadap massa yang menjadi sasarannya, karena sifatnya yang audio visual, yaitu gambar dan suara yang hidup. Dengan gambar dan suara, film mampu bercerita banyak dalam waktu singkat. Ketika menonton film penonton seakan-akan dapat menembus ruang dan waktu yang dapat menceritakan kehidupan dan bahkan dapat mempengaruhi audiens.
Dewasa ini terdapat berbagai ragam film, meskipun cara pendekatannya berbeda-beda, semua film dapat dikatakan mempunyai satu sasaran, yaitu menarik perhatian orang terhadap muatan-muatan masalah yang dikandung. Selain itu, film dapat dirancang untuk melayani keperluan publik terbatas maupun publik yang seluas-luasnya.

Pada umumnya film cerita bersifat komersial, artinya dipertunjukan di bioskop dengan harga karcis tertentu atau diputar di televisi dengan dukungan sponsor iklan tertentu. Film non cerita adalah film yang mengambil kenyataan sebagai subyeknya, yaitu merekam kenyataan dari pada fiksi tentang kenyataan. (Estu Miyarso, 2012).

Dalam dunia bisnis saat ini, promosi adalah sebuah hal yang sangat wajib untuk dilakukan tiap orang. Apabila sedang menjual sebuah produk, maka sangat disarankan untuk melakukan promosi dengan tepat dan menarik untuk para konsumen. Promosi akan semakin tampak penting seiring berjalannya waktu dan usaha.

Begitu pula dengan industri film saat ini, film yang sukses dipasaran tentu juga melibatkan kegiatan promosi yang tepat dan menarik. Promosi marketing dalam film dapat menjadi faktor yang 
menentukan besarnya antusiasme penonton terhadap suatu film. Sebuah film harus diimbangi dengan teknik marketing yang unik dan kreatif untuk menarik minat para penonton. Buat yang punya modal lebih, banyak produser yang menggunakan strategi pemasaran lewat promosipromosi yang dilakukan lewat media. Untuk memberikan kesan khusus kepada calon penonton.

Beberapa hal dalam promosi film adalah:

1. Mengidentifikasi Tema Film

Point ini termasuk menganalisa dan menemukan clue sebagai bahan pemicu (trigger) dalam merangsang publik agar muncul rasa penasaran pada film tersebut.

2. Design Film

Mainstream desain film saat ini, dalam konteks film komersial adalah realist. Menggunakan visualisasi dari adegan film yang telah diproduksi. Tentu dipilih dari adegan-adegan yang menarik, dan mampu "berbicara". Artinya design yang mampu memberikan stimulasi imajinasi penonton dalam bentuk trailer (cuplikan film).

3. Ekspose Produksi Film

Dengan membuat acara dalam bentuk event yang bertajuk seperti talkshow, met and great, dan konfrensi pers baik secara langsung ataupun melalui media social.

Dalam penelitian ini, penulis akan menjabarkan pembentukan desain film atau trailer dalam produksi sebuah film dengan menggunakan elemen plugin footage action movie essential elements dalam adobe after effect.

\section{METODOLOGI PENELITIAN}

Penelitian terdahulu dengan judul Produksi Film "Kita Indonesia" Sebagai Analisa Media Komunikasi Berbasis Multimedia oleh Supriyadi. (Tsabiet \& Supriyadi, 2018). Penelitian tersebut membahas tentang proses produksi sebuah karya audio visual bertema tentang Public Service Announcement (PSA) yang dimulai dari unsur pra produksi, produksi dan pasca produksi. Berdasarkan penelitian diatas, hubungan antara penelitian diatas sangat erat kaitannya untuk produksi tersebut, karena pembahasan ini menjadi media promosi dari produksi film tersebut. Promosi produksi film tersebut dalam bentuk trailer.

Selain itu, penelitian mengenai trailer tentang The Effectiveness of Film Trailers : Evidence from The College Student Market oleh Jerrick. (Jerrick, 2013). Hasil penelitian yang dilakukan oleh Jerrick mengungkapkan bahwa trailer secara efektif mendorong dan mempengaruhi audience untuk membayar dan menonton film yang diiklankan tersebut di bioskop.
Trailer merupakan preview atau cuplikancuplikan adegan yang menarik dari sebuah film, yang bertujuan untuk menarik minat penonton agar berkeinginan melihat film tersebut. Sedangkan perkembangan dunia film sendiri pada akhirakhir ini sangatlah maju dengan pesat. Banyak sekali adegan menarik yang sangat luar biasa ditampilkan pada beberapa film terkemuka di dunia saat ini. Seperti halnya trailer pada film-film Aquaman dan Avenger, dimana di dalamnya terdapat adegan menampilkan sebuah kota-kota rekayasa yang menyerupai aslinya dalam cerita tersebut dan ledakan-ledakan yang menghancurkan bangunan atau lingkungan disekitarnya. Tidak mungkin tempat-tempat seperti itu ada di bumi ini.

Dibutuhkan suatu teknik khusus atau yang sering disebut dengan special effect untuk membuat adegan-adengan tersebut. Pada penelitian ini, penulis nantinya akan membuat suatu sample atau contoh trailer, dimana terdapat cuplikan adegan yang banyak menggunakan special effect di dalamnya. Trailer yang nantinya akan dibuat, menceritakan tentang seorang pemuda berwajah lugu yang berasal dari luar angkasa. Namun dibalik wajahnya yang lugu itu, pemuda tersebut mempunyai kekuatan super yang dapat membunuh orang dan menghancurkan bumi dengan mudah. Pada adegan dimana pemuda tersebut melakukan pembunuhan dan penghancuran, akan ditampilkan adegan layaknya film-film terkemuka saat ini, seperti pembunuhan dengan darah yang menyembur dari tubuh seseorang dan berceceran, tubuh yang hancur terbakar, bangunan-bangunan yang hancur akibat ledakan dan lainya untuk mendapatkan kesan yang dramastis dan menarik.

Metode penelitian memiliki ruang yang sangat luas. Dilihat dari jenis penelitian, maka penelitian dapat dibedakan menjadi 3 klasifikasi, yaitu penelitian aplikatif, penelitian maksud, dan penelitian berdasarkan jenis informasi. Pada penelitian aplikatif, terdapat 2 jenis penelitian, yaitu penelitian murni dan terapan. Dalam pembuatan karya ini yang di gunakan adalah penelitian terapan. Penelitian terapan adalah penelitian yang hasilnya dapat digunakan langsung untuk menyelesaikan permasalahan yang di hadapi. (Arikunto, 2013).

Metode yang dapat digunakan didalam perancangan ini yaitu:

1. Tahap analisa

Tahapan analisa disini meliputi pengambilan data dari literatur, referensi akan plugin-plugin after effect yang digunakan, scenario dan storyboard.

2. Perancangan Karya

Untuk tahapan perancangan karya yang digunakan adalah proses pra produksi, proses produksi dan proses editing yaitu pembuatan special effect dengan mengimplementasikan footage action movie essential elements untuk 
videonya dan pembuatan trailer dengan teknik editing sebagai sampel atau contoh penggunaan plugin after effect sehingga film tersebut menjadi menarik penonton sebuah video.

\section{HASIL DAN PEMBAHASAN}

Membuat karya trailer, saat ini sangat mudah tepatnya dimudahkan. Salah satunya adalah karena kecanggihan teknologi yang sudah mendukung para pembuatnya, baik untuk profesional maupun para pehobi. Beragam kamera video digital, perangkat software memudahkan para pengguna. Ini bukan perihal teknologi saja, tapi ada tahapan yang harus dipatuhi oleh para pembuat sehingga proses-proses tersebut nantinya aan mempermudah bagi si pembuatnya ini.

\section{Tahap Analisa}

Storyboad

Storyboard merupakan kumpulan sketsa gambar yang disusun secara berurutan dan disesuaikan dengan naskahnya sehingga ide cerita bisa disampaikan dengan mudah. (Hart, 2008).

Di jaman sekarang storyboard dipakai di berbagai bidang, seperti perfilman, animasi, hingga dunia advertising. Pada prosesnya, sutradara dan pengarah fotografi akan membahas adegan-adegan secara lengkap, kemudian mereka akan menghubungi seniman storyboard untuk menerjemahkan idenya dalam rangkaian gambar. Dari sini akan tercipta rancangan shooting. Secara gamblangnya, storyboard ini akan memberikan gambaran jelas pada pemain serta kru supaya bisa bekerja dengan baik. Umumnya dalam storyboard ini ada tata letak visual adegan yang akan diambil. Tidak hanya itu, storyboard juga penting bagi editor agar ia bisa menyusun scene yang berbeda sesuai dengan skenario yang ditetapkan.

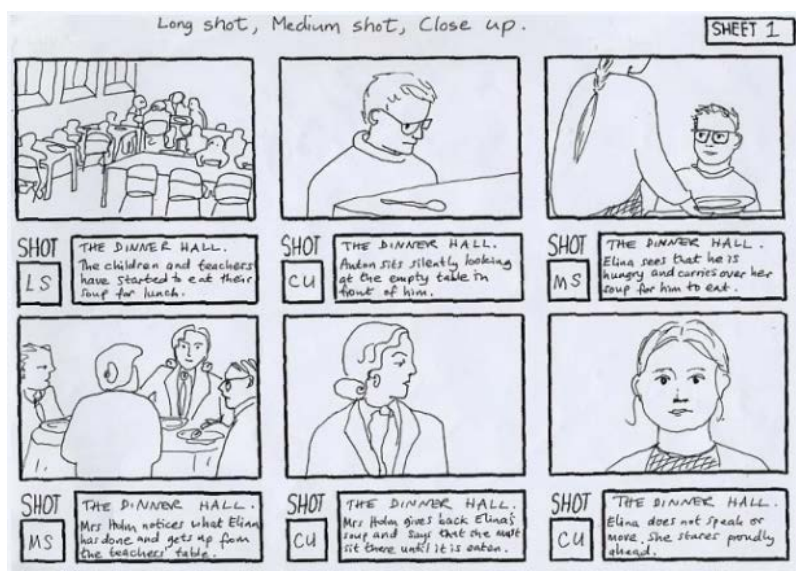

Gambar 1. Contoh Storyboard

Dalam pembuatan storyboard, ada beberapa hal yang perlu diperhatikan, antara lain ; prinsip penulisan, konsep, strategi dan proses perancangan grafis. Prinsip penulisan storyboard yang baik adalah Pesan visual harus kreatif (asli, luwes dan lancar), komunikatif, efisien dan efektif, sekaligus indah/estetis. Sedangkan konsep, strategi dan proses perancangan grafis yang baik untuk storyboard adalah 5W dan $1 \mathrm{H}$ (what, where, when, who, why dan how) serta mempunyai penyampaian pesan yang efektif dan efesien. (Dhimas, 2013).

\section{Video Editing}

Video editing adalah suatu proses memilih atau menyunting gambar dari hasil shooting dengan cara memotong gambar ke gambar (cut to cut) atau dengan menggabungkan gambar dengan menyisipkan sebuah transisi hingga menjadi suatu kesatuan yang utuh. (Hendratman, 2017).

Jenis editing sendiri ada dua, yaitu editing linear dan editing non-linear. Editing linear adalah proses pengeditan gambar satu persatu secara berurutan dari awal hingga akhir. Sehingga seandainya terjadi kesalahan dalam menyusun gambar maka harus diulangi kembali dari awal. Sedangkan editing non-linear (NLE) adalah proses pengeditan gambar secara acak atau tidak berurutan. Banyak sekali software editing yang bisa digunakan, seperti: Avid Composer, Final Cut Pro, Ulead Video, dan Adobe Premiere. Untuk editing film pendek kedua software editing terakhir sudah cukup bagus. Pada proses ini seorang editor tidak harus memulai pengeditan dari awal berurutan hingga akhir, tapi bisa memulainya dari mana saja tergantung materi mana yang sudah siap. Selain itu, editing juga dapat diklasifikasikan menjadi editing yang berbasis waktu (timeline) dan animasi atau pembuatan efek. Editing yang berbasis waktu hanya cenderung pada pemotongan video dan penggabungan video yang biasanya disisipi transisi. Sedangkan editing yang berbasis animasi atau efek adalah editing yang melibatkan pembuatan atau pengimplementasian dari sebuah animasi atau efek video.

\section{Adobe After Effect}

Adobe After Effect adalah sebuah software yang sangat professional untuk kebutuhan Motion Graphic Design. Dengan perpaduan dari bermacam-macam software design yang telah ada, After Effect menjadi salah satu software yang handal. Standar efek yang mencapai 50 macam lebih, yang sangat bisa untuk merubah dan menganimasikan obyek. Disamping itu, membuat animasi atau efek dengan Adobe After Effect juga bisa dilakukan dengan hanya mengetikan beberapa kode script yang biasa disebut dengan Expression untuk menghasilkan pergerakan yang lebih dinamis. (Perisic, 2013) 


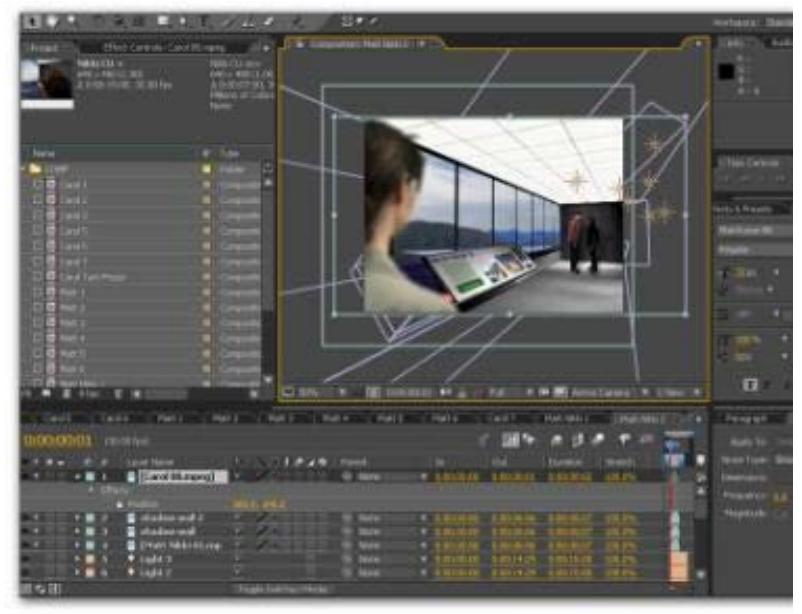

Gambar 2. Tampilan Adobe After Effect

Adobe After Effects memiliki fitur-fitur penting, misalnya Adobe After Effects memiliki alat untuk membuat Shape (seperti yang terdapat pada Adobe Photoshop). Pada Adobe After Effects terdapat Keyframe seperti yang terdapat pada Adobe Flash (cara menganimasikannya juga hampir sama). Terdapat juga Expression yang hampir mirip dengan Action Script pada Flash, dan masih banyak lagi yang lain.

Software ini menjadi primadona dalam membuat effect-effect spesial pada animasi video. Tetapi Karena keterbatasan effect yang ada pada Adobe After Effect itu sendiri, maka tidak jarang para editor menggunakan effect tambahan / plug-ins yang dibuat oleh produsen selain Adobe. Banyak sekali plugins yang terdapat pada Adobe After Effect ini. Sebagai contohnya, plugins yang biasa digunakan dalam dunia editing profesional, tentu saja plug-ins ini harus full version. Dalam Adobe After Effect ada beberapa jenis plugin yang biasa digunakan yaitu Preset, Script dan Plugin.

\section{Preset}

Preset dalam adobe after effect adalah kumpulan efek yang sudah tersimpan dalam instalan pada saat software tersebut atau dengan kata lain efek yang sudah disediakan oleh adobe itu sendiri.

\section{Script}

Script after effect adalah kumpulan kode perintah untuk melakukan sesuatu pada after effect. Script juga dapat melakukan bermacam-macam perintah di after effect, dari pembuatan layer sampai ke proses rendering. Script tidak hanya membantu mempercepat dalam pembuatan efek tapi dapat juga untuk fungsi fungsi lainnya. Script menggunakan bahasa coding Extend Script. Dalam pembuatannya, Script tidak dapat langsung ditulis dan diuji dalam After Effects. Sebaliknya, pencipta script biasanya menggunakan ExtendScript Toolkit yang termasuk dalam Adobe Creative Cloud. The ExtendScript toolkit dapat digunakan untuk menulis skrip untuk sebagian besar program termasuk dalam Creative Cloud, bukan hanya After Effects. File Script biasanya tersimpan dalam format .jsxbin dan semacamnya.

\section{Plugin}

Plugin merupakan fungsi tambahan pada after effect yang melampaui fungsi dari after effect itu sendiri. Dengan kata lain, plugin adalah pihak ketiga yang memberi fitur tambahan pada after effect.

Plugin menggunakan kode eksternal yang pada dasarnya untuk pembuatan software baru yang dapat terintergrasi dengan after effect. Beberapa plugin yang sudah ternama antara lain Element 3D, Optical Flares, Trapcode Particular dan footage action movie essential elements

\section{Footag}

Asal usul istilah "footage" berasal dari film bisu $35 \mathrm{~mm}$ yang secara tradisional diukur dalam satuan kaki dan frame. Fakta bahwa film diukur berdasarkan panjang dalam kamar pemotongan dan ada 16 frame (format film 4-perf) per kaki pada film 35mm--yang kira-kira mewakili 1 detik dari film bisu, menjadikan footage sebagai ukuran lazim untuk film. Istilah ini kemudian digunakan secara kiasan untuk mendeskripsikan materi gambar bergerak dalam berbagai bentuk. Rekaman televisi, terutama cuplikan berita, seringkali diperdagangkan di jaringan-jaringan televisi, tetapi rekaman yang bagus biasanya menuntut harga tinggi. Jumlah sebenarnya tergantung pada durasi, usia, dan ukuran penonton yang diharapkan. (Ablan, 2002).

Dalam film dan animasi, footage adalah bahan atau material mentah, yang merupakan hasil dalam bentuk asli dari kamera. Untuk membuat sebuah klip video, film ataupun animasi yang lengkap, footage harus diedit dan diolah terlebih dahulu. Secara umum, footage sering kali digunakan dalam hal olah video, film dan animasi, seperti special effect dan archive material. Footage hanya merujuk pada gambar yang direkam, seperti stok film, kaset video atau klip digital.

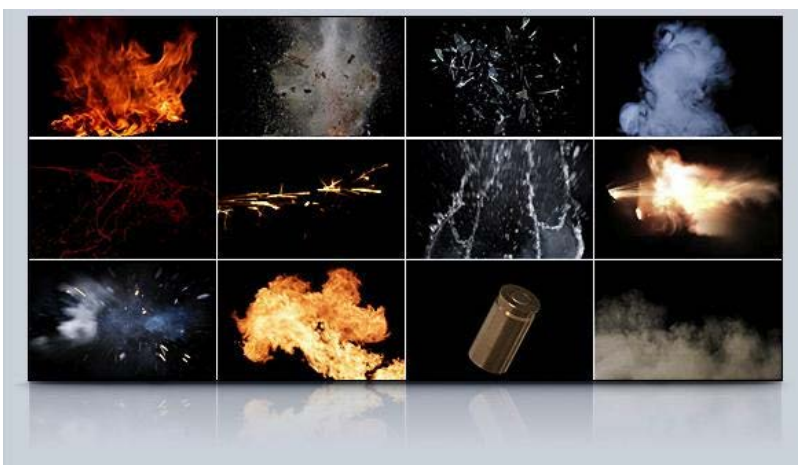

Gambar 3. Tampilan Action movies essential footage 
Sebuah footage yang baik adalah footage yang mempunyai tingkat kompabilitas yang tinggi terhadap semua software pengolahan video ataupun animasi. Selain itu juga mempunyai data atau material yang benar- benar mentah, sehingga dapat sepenuhnya diolah oleh pengguna.

\section{Special Effect}

Special Effect atau efek spesial di dalam bahasa Indonesia, sering disingkat SFX atau SPFX banyak digunakan di dalam dunia film, pertelevisian dan hiburan. Dengan definisi ini, efek spesial tidak cuma terdapat dalam film, seperti yang diketahui masyarakat awam. Efek spesial tidak hanya berwujud gambar, tetapi memiliki pengertian luas. Jadi sebuah pertunjukan musik dengan segala macam sinar laser, kembang api dan lainnya, hal tersebut dapat pula dikatagorikan sebagai efek spesial. Apapun bentuknya, efek spesial digunakan untuk meningkatkan dampak suatu obyek terhadap indera manusia. Obyek tersebut bisa berupa tontonan, gambar atau pertunjukan. Dengan demikian, diharapkan efek spesial bisa meningkatkan ketertarikan seseorang terhadap obyek tersebut. (Didik Wijaya, 2006).

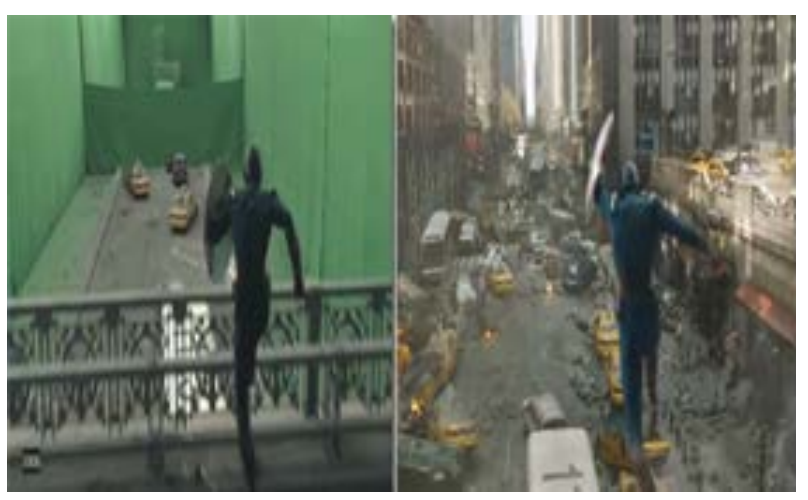

Gambar 4. Special effect

Efek spesial merupakan kombinasi dari seni dan teknologi. Dari sisi teknologi, tidak cuma penguasaan teknologi yang digunakan, namun juga pengetahuan bagaimana indera manusia menangkap gambaran yang akan diterima oleh otak. Sedangkan sisi seni, berperan tentang bagaimana teknologi tersebut digunakan atau mencapai hal tersebut. Yang akan dilakukan para ahli efek spesial adalah bagaimana menipu indera manusia, terutama audio-visual, bahwa seakan-akan hal tersebut terjadi.

\section{Trailer}

Trailer dalam istilah umum dalam dunia perfilman yang merujuk kepada upaya promosi sebuah film yang akan segera tayang melalui video, memuat plot inti cerita dalam film, termasuk pemeran, sutradara, produser, distributor dan waktu tayang film tersebut. Panjang sebuah video trailer lebih kurang 2-3 menit. Trailer kali pertama dikenal pada tahun 1913 untuk mempromosikan film The Pleasure Seekers di Amerika Serikat.

Di Indonesia, trailer film mulai menggejala pada pertengahan dasawarsa 1990-an, ketika internet mulai mewabah di seluruh penjuru dunia. Bahkan saat ini, trailer film melalui video di internet seakan sudah menjadi media promosi paling efektif dalam promosi sebuah film. Beberapa produser film blockbuster bahkan merilis video trailer film mereka setahun sebelum waktu tayangnya di gedung bioskop.

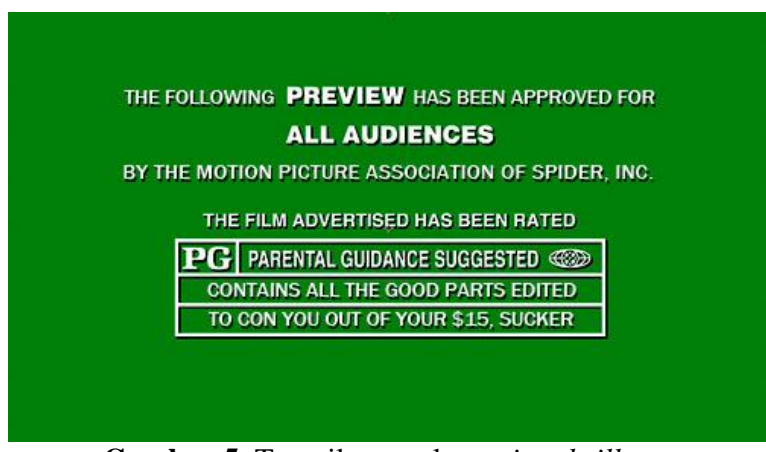

Gambar 5. Tampilan awal opening thriller

Trailer sebaiknya menstimulasi perhatian penonton ke sebuah film secara cepat dan juga menunjukan apa yang disuguhkan film tersebut tanpa memberikannya terlalu banyak jalan cerita. Trailer adalah bentuk advertising dari film. Ditunjukan sebelum penayangan sebuah film di bioskop. Kata Trailer sendiri datang karena awalnya, ditayangkan di akhir penayangan film. Tetapi karena pada praktiknya banyak penonton meninggalkan bioskop setelah sebuah film selesai, maka pemutarannya diganti menjadi sebelum sebuah film tayang. Meskipun demikian nama trailer tetap atau tidak diganti dengan kata yang lainnya.

Sebuah trailer di lain pihak dapat disebut bentuk kecil dari film. Sebuah trailer dapat memiliki durasi 1 menit sampai 5 menit. Biasanya hanya berisi point penting untuk menarik penonton. Dan mengklasifikasikan trailer lebih mudah dari pada mengklasifikasikan keseluruhan film.

\section{Perancangan Karya}

Pada pembuatan trailer kali ini, penulis menggunakan media yang diklasifikasikan menjadi dua kategori, yaitu yang berupa hardware (perangkat keras) dan yang berupa software (perangkat lunak).

\section{Perangkat Keras (Hardware), yaitu :}

Perangkat keras yang digunakan pada produksi ini digunakan baik dalam proses recording maupun 
editing. Perangkat tersebut antara lain adalah :

1. Kamera SLR Canon 5D

2. Lensa.

3. Tripod.

4. SD card dan HDD.

5. Kain untuk Greenscreen

6. Art properties

7. Seperangkat Komputer Multimedia.

Perangkat Lunak (Software), yaitu :

Perangkat lunak yang digunakan pada produksi ini digunakan pada saat proses editing. Perangkat tersebut antara lain adalah :
1. Footage Action Movie Essential Elements
2. Sound/Audio File
3. Adobe After Effect
4. Adobe Premiere

Berikut ini tahapan-tahapan dalam menyelesaikan perancangan karya tersebut:

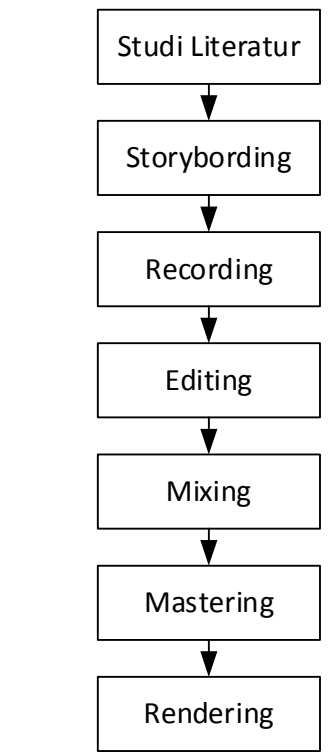

Gambar 6. Bagan metodologi

\section{Penuangan Ide}

Pada produksi ini, akan dibuat sebuah trailer yang menceritakan tentang seorang pemuda berwajah lugu yang berasal dari luar angkasa. Namun dibalik wajahnya yang lugu itu, pemuda tersebut mempunyai kekuatan super yang dapat membunuh orang dan menghancurkan bumi dengan mudah. Pada adegan dimana pemuda tersebut melakukan pembunuhan dan penghancuran, akan ditampilkan adegan layaknya film- film terkemuka saat ini, seperti pembunuhan dengan darah yang menyembur dari tubuh seseorang dan berceceran, tubuh yang hancur terbakar, ledakan dasyat yang terjadi pada sebuah gedung dan lainya untuk mendapatkan kesan yang dramastis dan menarik. (Naratama Rukmananda, 2014)

\section{Perencanaan Adegan}

Adegan yang nantinya akan dibuat dengan menggunakan special effect, antara lain adalah sebagai berikut :

Super jump : adalah adegan dimana aktor utama berlari dan melompat ke udara dengan kecepatan yang luar biasa. Sehingga saat melompat, daerah/tempat yang digunakan aktor utama sebagai tumpuan menghasilkan hempasan debu, batuan yang terlontar dan tanah yang retak akibat lompatan tersebut.

Super crash : adalah adegan dimana aktor utama mendarat dengan kekuatan yang luar biasa. Sehingga saat mendarat, daerah/tempat yang digunakan aktor utama sebagai tumpuan menghasilkan hempasan debu, pecahan tanah yang terlontar dan tanah yang retak akibat pendaratan tersebut.

Burned and destroyed body : merupakan adegan dimana aktor pendukung tubuhnya terbakar dan hancur berkeping-keping yang dikarenakan oleh kekuatan dari aktor utama. Pada adegan ini, nantinya akan ditampilkan sebuah api yang melahap tubuh aktor pendukung. Bersamaan dengan api yang melahap tubuh aktor pendukung, muncul pula percikan api, kepingan tubuh aktor pendukung yang berhamburan dan asap yang timbul akibat api yang membakar tubuh aktor pendukung tersebut.

Scattering blood sprayed : adalah adegan dimana aktor pendukung tubuhnya hancur berkepingkeping dan bersamaan dengan itu keluar darah yang menyembur dari tubuh aktor pendukung itu. Ada dua skenario yang menggunakan jenis adegan ini, yaitu; aktor pendukung yang tubuhnya hancur dikarenakan oleh kekuatan aktor utama dan aktor pendukung yang kepalanya hancur karena bunuh diri /menembak kepalanya dengan pistol (dikendalikan oleh kekuatan aktor utama).

Explosion : merupakan adegan dimana terjadi ledakan, semburan api dan hempasan dari benda/batuan yang dikarenakan oleh ledakan tersebut. Ada dua skenario yang menggunakan jenis adegan ini, yaitu ; ledakan pada sebuah gedung yang dikarenakan oleh kekuatan aktor utama. Menampilkan api yang menyembur, asap yang keluar dan hempasan dari batuan gedung tersebut. Dan skenario mobil meledak yang dikarenakan oleh kekuatan aktor utama. Juga menampilkan api yang menyembur yang keluar akibat ledakan tersebut.

Muzzle flashes : adegan dimana terjadi aksi baku tembak. Menampilkan aktor pendukung yang menembak menggunakan pistol. Dan pada waktu yang bersamaan, ujung pistol yang 
digunakan akan muncul percikan api yang menunjukan pistol tersebut mengeluarkan puluru.

Warp face : adalah adegan dimana aktor utama menunjukan wujud aslinya. Menampilkan wajah aktor utama yang awalnya berwujud manusia biasa lalu berubah menjadi wujud devil yang menyeramkan.

Kemudian akan dibuat juga beberapa text effect yang akan dibuat dengan menggunakan special effect. Text effect tersebut digunakan untuk memperkenalkan tokoh-tokoh yang ada dalam trailer ini. Dan dapat juga digunakan untuk memberikan informasi mengenai beberapa hal dalam trailer yang akan dibuat ini.

\section{Perencanaan footage}

Adegan-adegan yang akan dibuat dengan menggunakan special effect nantinya akan membutuhkan beberapa footage. Berikut ini adalah beberapa jenis footage pada footage action movie essential elements yang akan digunakan pembuatan untuk trailer.

1. Explosions element : merupakan footage atau material berupa ledakan (sembuaran api).

2. Fire element : merupakan footage atau material yang berupa api biasa.

3. Blood element : merupakan material berupa darah manusia yang menyembur.

4. Dust element : merupakan footage yang berupa hempasan debu dengan kepekatan yang berbedabeda.

5. Sparks element : merupakan material yang berupa percikan api yang terhempas.

6. Muzzle flash element : merupakan footage berupa percikan api yang biasanya terdapat pada ujung pistol.

7. Smoke element : merupakan footage berupa asap yang keluar dan bergerak biasa.

8. Smoke charges element : merupakan material berupa asap yang timbul akibat ledakan.

9. Debris element : merupakan footage berupa runtuhan dari beberapa material.

10. Glass element : merupakan material berupa kaca yang terhempas.

\section{Storyboarding \& Storytelling}

Storyboarding dan Storytelling merupakan awal dari pembuatan trailer. Pada tahapan ini adalah penuangan segala ide cerita atau konsep dari alur trailer yang akan dibuat, mulai dari opening trailer, pengenalan tokoh hingga menampilkan adegan- adegan yang menarik. Dalam hal ini, penuangan ide cerita berupa urutan gambar yang terdapat informasi didalamnya, seperti deskripsi gambar, durasi, pengambilan gambar, jenis pengambilan gambar, narasi, dan lainya.

\section{Recording}

Tahapan recording adalah tahapan dimana dilakukan pengambilan gambar utama, baik gambar bergerak maupun gambar diam. Alat yang akan digunakan pada tahapan ini adalah kamera SLR Canon 5D. Pada tahapan ini, pengambilan gambar akan dilakukan dengan menyesuaikan atau membaca semua ketentuanyang ada dalam storyboard.

Sedangkan untuk kualitas gambar/video yang akan digunakan dalam tahapan recording ini, menggunakan kualitas gambar full HD (High Definition). Agar video yang dihasilkan mempunyai kualitas gambar yang bagus dan ukuran gambar yang besar. Sehingga tidak akan ada keterbatasan atau masalah dalam pengolahan gambar/video yang berhubungan dengan kualitas atau ukuran gambar.

\section{Editing}

Editing merupakan proses pengolahan gambar baik gambar gerak maupun gambar diam yang telah direkam sebelumnya. Pada tahapan ini menggunakan dua software video editing, yaitu Adobe After Effect dan Adobe Premiere. Adobe After Effect pada proses editing digunakan untuk membuat efef-efek khusus yang telah direncanakan pada storyboard sebelumnya. Sedangkan Adobe Premiere digunakan untuk memotong video atau mengolah video biasa tanpa menggunakan atau membuat efek. Pada tahapan editing ini, lebih cenderung kedalam penggunaan software video editing Adobe After Effect. Karena dalam pengerjaan proyek akhir ini, movie trailer yang dibuat lebih fokus kedalam pembuatan efek-efek khusus dengan menggunakan teknik implementasi footage action movie essential elements pada Adobe After Effect. Sebaiknya editor terlebih dahulu membaca skenario serta berdiskusi dengan sutradara, dengan demikian ia sudah paham cerita film pendek tersebut sebelum ia melakukan penyuntingan gambar. Setelah gambar ada di dalam komputer, selanjutnya editor sudah bisa melakukan pemilihan gambar, lalu menyusun shot menjadi scene atau serangkaian adegan. Seperti halnya sutradara, editor semestinya memposisikan sebagai story teller, ia harus bisa bertutur dengan pemotongan serta penyambungan gambar tadi. Jadi, editor tidak asal motong serta menyambung saja. Setiap sambungan serta pemotongan harus memiliki makna dan pesan.

\section{Mixing}

Pada tahapan ini dilakukan penggabungan antara hasil editing adegan satu dengan adegan yang lainnya. Untuk proses mixing yang dilakukan, menggunakan software video editing Adobe Premiere. File yang dimasukan/di-import ke dalam Adobe Premiere bukan project file dari Adobe After Effect yang berekstensi .aep , melainkan berupa video yang telah dirender sebelumnya pada Adobe After Effect. 
Tidak hanya penggabungan video antara hasil editing adegan satu dengan yang lainya. Pada tahapan mixing juga dilakukan penggabungan musik/sound. Musik yang digabungkan menjadi background musik dan sound effect pada movie trailer yang akan dibuat.

\section{Mastering}

Merupakan suatu tahapan dimana dilakukannya pengecekan ulang untuk memastikan bahwa suatu produk siap diproduksi. Pada tahapan ini hasil mixing dilakukan pengecekan kembali. Apakah semua ketentuan pada storyboard telah dilakukan dengan baik dan benar, mulai dari kualitas gambar, urut-urutan gambar, kesempurnaan efek, ketentuan audio hingga kelayakan video untuk dikonsumsi penonton.

\section{Rendering}

Tahapan ini adalah tahapan terakhir yang dilakukan dalam pengerjaan proyek akhir ini. Rendering merupakan tahapan dimana dilakukannya pengkonversian atau proses untuk mengubah file project menjadi sebuah file yang dapat dijalankan di media lain. Pada tugas akhir ini, file project yang dimaksud adalah hasil dari mixing dan editing pada Adobe Premiere, kemudian dirubah menjadi file video (movie trailer) sehingga dapat dijalankan di media/player lainnya (tidak hanya pada Adobe Premiere). Format video yang dihasilkan ditentukan pada tahapan rendering ini. Pada proyek akhir ini, video (movie trailer) yang dihasilkan menggunakan format video quick time dengan menggunakan video codec H.2624.

\section{KESIMPULAN}

Film merupakan salah satu alat yang ampuh di tangan orang yang mempergunakannya secara efektif untuk sesuatu maksud terutama terhadap masyarakat kebanyakan dan juga anak-anak yang memang lebih banyak menggunakan aspek emosinya dibanding aspek rasionalnya, dan langsung berbicara ke dalam hati sanubari penonton secara meyakinkan. Film juga sangat membantu dalam proses pembelajaran, apa yang terpandang oleh mata dan terdengar oleh telinga, lebih cepat dan lebih mudah diingat daripada apa yang hanya dapat dibaca saja atau hanya didengar saja.

Adanya trailer maka akan dapat mempengaruhi masyarakat untuk menonton film yang ada tersebut atau memancing minat dan pencarian informasi, mendorong pemahaman informasi, membantu orang untuk menontonnya. Trailer lebih memiliki daya tarik karena trailer film mampu menampilkan cerita yang terdapat dalam suatu film secara lebih nyata melalui cuplikan adegan-adegan film. Masyarakat dapat mengetahui tokoh-tokoh yang berperan dalam film tersebut.

Berdasarkan hal ini, dapat disimpulkan bahwa plugin pada Adobe After Effect dapat digunakan untuk membuat suatu adegan yang menggunakan special effect di dalamnya.

Pembuatan sebuah adegan yang melibatkan ledakan pada mobil, gedung dan pembunuhan tidak harus meledakan bangunan- bangunan/mobilmobil yang ada ataupun benar-benar membunuh orang. Sehingga dengan menambah unsur Sound effect sangat mendukung kesempurnaan dan penyampaian adegan special effect (visual) yang telah dibuat.

\section{REFERENSI}

Ablan, D. (2002). Digital Cinematography \& Directing. United States: New Riders.

Arikunto, S. (2013). ProsedurPenelitian Suatu Pendekatan Praktik. Yogyakarta: Rineka Cipta.

Dhimas, A. (2013). Cara Mudah Merancang Storyboard Untuk Animasi Keren. Yogyakarta: Taka Publisher.

Didik Wijaya. (2006). Total Training Max : Special Effects. Jakarta: Escaeva.

Effendy. (2011). Ilmu Komunikasi: Teori dan Prakteknya. Bandung: Remaja Rosdakarya.

Estu Miyarso. (2012). PERAN PENTING SINEMATOGRAFI DALAM PENDIDIKAN PADA ERA TEKNOLOGI INFORMASI \& KOMUNIKASI.

Hart, J. (2008). The Art Of Storyboard : A Filmmaker's Introduction. United States: Focal Press.

Hendratman, H. (2017). The Magic of Adobe Premiere Pro. Jakarta: Informatika.

Jerrick, D. (2013). The Effectiveness of Film Trailers: Evidence from the College Student Market. UW La Crosse - Journal of Undergraduate Research, 16, 1-13. https://doi.org/10.1080/13527266.2010.53807 1

Naratama Rukmananda. (2014). Menjadi Sutradara Televisi. Jakarta: Grasindo.

Perisic, Z. (2013). Visual Effects Cinematography. United States: Focal Press.

Tsabiet, M., \& Supriyadi, S. (2018). Produksi Film PSA “Kita Indonesia” Sebagai Media Komunikasi Berbasis Multimedia. Jurnal Komunikasi, 9(2), 211-218. https://doi.org/10.31294/JKOM.V9I2.4370

\section{PROFIL PENULIS}

Merupakan staff pengajar pada STMIK Nusa Mandiri Jakarta. Untuk bidang tulis menulis, selain 
buku Broadcasting Televisi Teori \& Praktik, sebelumnya ia juga aktif menulis artikel di BSI NewsLetter, Majalah SDA Asia dan Broadcast Magz. Antara komputer dan broadcasting inilah yang membuatnya menjadi tenaga pengajar yang mumpuni tanpa melupakan latar belakang di bidang komputer. Untuk beberapa tulisannya bisa dilihat pada web pribadinya di http://pojokspy.blogspot.com dimana banyak mahasiswa yang tertarik dan menerapkan materi perkuliahan yang didapat pada blog tersebut 